\title{
Produção de biodiesel como um método de aprendizagem para alunos do ensino médio
}

\author{
Giacomin, I. J. F'.;Barañano, A. S $2^{2^{*}}$ \\ 1Graduação em Engenharia Química, Universidade Federal do Espírito Santo, Alegre, ES, Brasil. \\ 2 Programa de Pós-Graduação em Engenharia Química, Curso de Graduação em Engenharia Química. \\ *e-mail: audrei@pq.cnpq.br \\ Departamento de Engenharia Rural, CCA, Universidade Federal do Espírito Santo - UFES, Alegre , ES, Brasil
}

\begin{abstract}
Resumo
Um tema como o biodiesel é uma oportunidade de combinar vários assuntos e áreas do conhecimento. Nesse sentido, o objetivo deste trabalho é aproximar os princípios de química da realidade de estudantes de ensino médio, através do ensino teórico e experimental da produção de biodiesel a partir do óleo de fritura usado. Esse estudo visa tornar acessível, descomplicado e interessante o estudo de ciências bem como demonstrar suas aplicações no cotidiano. Para tal, exploraram-se conceitos de química orgânica e algumas definições fundamentais dos processos químicos. Na parte experimental deste projeto, realizou-se a reação de transesterificação e a purificação do produto para se obter 0 biodiesel, no laboratório da escola EEEFM Miguel de Sanctis e no laboratório de Engenharia Química da UFES. Além disso, houve a apresentação do trabalho pelas alunas de ensino médio na II Mostra de Química e Física realizada pela escola EEEFM Miguel de Sanctis. O tema deste projeto é atual e proporciona a discussão sobre sustentabilidade, economia e energia. Dessa forma, acredita-se que o projeto contribui decisivamente na formação dos estudantes, no seu envolvimento com problemas da sociedade, como também nas suas perspectivas para o futuro.
\end{abstract}

\begin{abstract}
A theme such as biodiesel is an opportunity to combine many subjects and knowledge areas. In work, the main purpose is to approach chemistry principals to high school students reality, through theoretical and experimental biodiesel production teaching from used frying oil. This study aims to make accessible, uncomplicated and interesting the science study as well as demonstrate their applications in daily life. For this purpose, it explores organic chemistry concepts and some basic chemical processes definitions. In the experimental part of this project were done the transesterification reaction and product purification to obtain biodiesel in the laboratory of the school EEEFM Miguel de Sanctis and in the Chemical Engineering laboratory at UFES. In addition, there was the work presentation by high school students in anchemistry and physics exhibition conducted by school EEEFM Miguel de Sanctis. This project theme is current and provides a discussion of sustainability, economy and energy. Thus, it is believed that the project contributes decisively in students training and their engagement with society's problems, as well as its future prospects.
\end{abstract}

Keywords (Palavras chaves): Aprendizagem, biodiesel, sustentabilidade.

\section{Introdução}

Há algum tempo vem-se discutindo o correto destino que devemos dar ao lixo que produzimos, pois os efeitos da degradação ambiental decorrente das atividades domésticas e industriais estão atingindo níveis alarmantes. Nas indústrias alimentícias, restaurantes, lanchonetes e nas nossas residências é gerado um resíduo que na maioria das vezes é descartado de forma incorreta: o óleo usado em frituras.
Devido à alta demanda de energia no mundo industrializado, tem-se desenvolvido tecnologias para produzir energia de fontes renováveis de menor impacto ambiental que os meios existentes, com a possibilidade de substituir total ou parcialmente os combustíveis de fontes não renováveis. Muitos países estão desenvolvendo programas de produção de biodiesel como uma alternativa sustentável de geração de energia, o que impacta positivamente em termos ambientais e econômicos. ${ }^{3}$

O biodiesel é um combustível biodegradável e 
renovável. Quimicamente é definido como uma mistura de ésteres alquímicos de ácidos graxos de cadeia longa derivados de óleos vegetais como o óleo de soja, girassol, mamona, ou ainda de gorduras animais. Atualmente o método mais utilizado para a produção de biodiesel é através da reação de transesterificação, pois as características físico-químicas dos ésteres de ácidos graxos obtidos são semelhantes as do óleo diesel. ${ }^{4}$

Óleos vegetais usados em frituras também podem ser utilizados para a obtenção do biocombustível, propiciando a reciclagem do resíduo. Dessa forma é possível reduzir a poluição gerada pelo descarte do óleo além de reduzir o custo da matéria prima para produção de biodiesel. O produto obtido é comparável ao biodiesel produzido de óleo refinado. ${ }^{2}$

A transesterificação é uma reação orgânica (Figura 1) na qual um triglicerídeo, presente nos óleos e gorduras, e um mono álcool de cadeia curta, geralmente metanol ou etanol, na presença de um catalisador (ácido ou base) reagem produzindo uma mistura de ésteres alquílicos de ácidos graxos (biodiesel) e glicerol. ${ }^{1}$
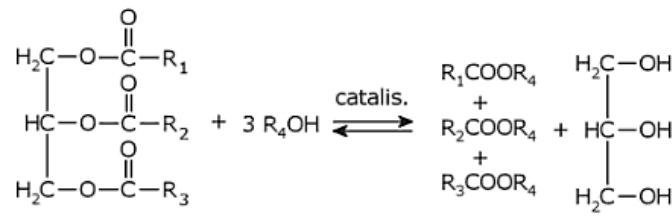

Figura

1 -Reação de transesterificação

Fonte: Da Silveira, 2011. p 49.

Os alcoóis que devem ser usados como reagentes na reação de transesterificação são aqueles que possuem baixa massa molecular, como o metanol, etanol, propanol e butanol. Entre esses, o metanol é o mais utilizado, pois, além do seu baixo custo na maioria dos países, sua cadeia curta reage rapidamente com o triacilglicerídeo o que proporciona a separação simultânea da glicerina, entretanto esse álcool é muito tóxico, por isso o etanol também é utilizado. ${ }^{2} \mathrm{O}$ glicerol, subproduto da reação, também é um álcool e possui valor econômico agregado, uma vez que pode ser utilizado em empresas como a farmacêutica, alimentícias e de cosméticos.

$O$ etanol pode ser um reagente mais interessante em relação ao metanol, pois é produzido a partir de fontes renováveis, enquanto o metanol é produzido de gás natural (fonte não renovável). ${ }^{5}$ Entretanto, apresenta alguns inconvenientes, pois forma emulsões muito facilmente tornando o processo de purificação dos produtos finais mais complicado. ${ }^{6}$

$\mathrm{Na}$ produção de biodiesel, o catalisador tem papel significativo, pois, sem eles, o processo de transformação de triglicerídeos em biodiesel é muito lento e economicamente inviável. ${ }^{3}$ Os catalisadores são compostos que aceleram as reações químicas sem nelas serem consumidos. Para a reação de transesterificação podem ser utilizados catalisadores ácidos, básicos e enzimas. 5 Neste experimento, utilizou-se a catalise básica pois apresenta vantagens em relação as demais: pode ser realizada a temperatura ambiente e, mesmo assim, é mais rápida do que a catalise ácida (que necessita ser realizada em altas temperaturas).

No processo de aprendizagem, a vivência de situações reais é extremamente importante para a compreensão de vários conteúdos. Por isso, a proposta deste trabalho é envolver os alunos do ensino médio, de forma a colocar em prática o que é aprendido na sala de aula, já que a síntese de biodiesel a partir do óleo de fritura abrange conhecimentos de química orgânica na transformação de um resíduo a um produto de valor. Este tema é muito interessante, pois engloba desde a aprendizagem de química e de processos químicos até energia e educação ambiental.

\section{Materiais e métodos}

Durante os cinco primeiros meses de atividade, quatro alunas de ensino médio estudaram tópicos em química orgânica que incluíram: funções, reações orgânicas, catalisadores e algumas definições fundamentais de processos químicos.

Como forma de conclusão desta etapa, as estudantes realizaram um estudo sobre dois temas: matériasprimas para produção de biodiesel e comparação entre diesel de petróleo e biodiesel. Tal estudo culminou em um seminário, que consistiu em apresentação oral com slides.

Posteriormente, para a aplicação da parte teórica, as estudantes realizaram a produção de biodiesel a partir de óleo de soja novo, no laboratório da escola EEEFM Miguel de Sanctis. A metodologia da obtenção do biodiesel seguiu as seguintes etapas:

Pesou-se cerca de $0,8 \mathrm{~g}$ de $\mathrm{NaOH}$ e, com o auxilio de 


\section{Blucher Proceedings \\ VI Encontro Científico de Física Aplicada}

Blucher

um bastão de vidro, dissolveu-o em um béquer contendo $60 \mathrm{~mL}$ de álcool etílico. Em seguida, mediu-se em uma proveta $200 \mathrm{~mL}$ de óleo de soja, novo ou usado (este último foi filtrado para remover as partículas sólidas) e transferiu-se para um béquer de $1000 \mathrm{~mL}$. A este béquer, adicionou-se a solução de álcool etílico $+\mathrm{NaOH}$ e colocou-se na chapa aquecedora, sobre a qual permaneceu durante uma hora, com agitação e a $60^{\circ} \mathrm{C}$.

Após o tempo de reação, adicionou-se cerca de $2 \mathrm{~g}$ de $\mathrm{NaCl}, 100 \mathrm{~mL}$ de água destilada e $50 \mathrm{~mL}$ de álcool etílico, e deixou-se sob agitação e aquecimento por mais 1 min. A água e o etanol ajudam a separação das fases pois se solubilizam na fase que contem o glicerol, já o sal contribui para conter a formação de sabão, que é um produto indesejado. ${ }^{7}$

Posteriormente, transferiu-se a solução para um funil de separação e aguardou-se a separação das fases, por cerca de 2 horas. Após a separação das fases, onde a fase superior é o biodiesel e a inferior é o glicerol, a válvula do funil de separação foi aberta e toda a fase mais pesada removida. Em seguida, retirou-se o biodiesel em outro béquer. Nesta etapa o biodiesel estava com uma aparência muito turva, por isso, foi necessária a filtração. Com o auxilio de um bastão de vidro transferiu-se o biodiesel bruto para um funil que já estava com um papel de filtro e aguardouse a filtração. Ao fim, transferiu-se o biodiesel filtrado para um recipiente fechado.

A partir dos conhecimentos teóricos e experimentais adquiridos, as estudantes apresentaram o projeto em um evento organizado pela escola EEEFM Miguel de Sanctis, a II Mostra de Química e Física. Para a qual foram confeccionados, pelas alunas de ensino médio sob supervisão, panfletos educativos sobre a reciclagem do óleo de fritura usado, como também um banner explicativo sobre todas as etapas da reação de transesterificação.

$\mathrm{Na}$ etapa final, realizou-se a reação de transesterificação com o óleo usado em frituras no laboratório da engenharia química da Universidade Federal do Espírito Santo - campus Alegre onde, além da reação, mediu-se a viscosidade no aparelho viscosímetro, do óleo de soja novo, óleo de soja usado em fritura e o biodiesel purificado e calculou-se o rendimento.

Para o cálculo do rendimento da reação de transesterificação, a partir da massa de $350 \mathrm{~mL}$ de óleo de soja novo e de biodiesel obtido, utilizou-se a equação (1):

$$
\text { 96 rendimento }=\frac{\operatorname{mrax} d \mathrm{datar}}{\operatorname{man} d \mathrm{dalss}} * 100
$$

\section{Resultados e discussões}

Como um dos principais resultados desde projeto, temse um maior aproveitamento da química orgânica que é ensinada nas escolas, associando-a a assuntos do dia a dia, que envolvem sustentabilidade e reciclagem, como também tem-se o desenvolvimento da oratória das estudantes de ensino médio, promovido pela participação das mesmas em seminários e mostras de ciências. Além disso, acredita-se que o envolvimento das estudantes em atividades, em conjunto com a Universidade, reduz a percepção de distanciamento do ensino superior e desperte o interesse e vontade de continuar os estudos e ingressar em cursos de graduação.

$\mathrm{Na}$ II Mostra de Química e Física, realizada na escola EEEFM Miguel de Sanctis, as estudantes apresentaram grande desenvoltura ao falar sobre a produção de biodiesel, interagindo com todos os alunos e professores que visitaram o estande e demonstrando a influência dos conhecimentos repassados no seu desenvolvimento como estudante.

Em relação ao experimento de produção de biodiesel, tem-se que o produto obtido apresentou coloração amarela e cristalina, não possuindo materiais em suspensão ou sedimentos, ou coloração turva, que poderia ser associado à presença de água. Verificada a ausência destes contaminantes, o biodiesel pode ser classificado como límpido e isento de impurezas. ${ }^{8}$

Para o calculo do rendimento da reação as massas de óleo de soja novo e de biodiesel foram, respectivamente, $316,36 \mathrm{~g}$ e $318,72 \mathrm{~g}$, portanto 0 rendimento foi de $100,75 \%$. Tal resultado demonstra que as estudantes realizaram o experimento com facilidade, uma vez que o processo é simples e evidenciando que é adequado ao propósito. Ressaltase que rendimento superior a $100 \%$ já era esperado, uma vez que na forma de cálculo utilizada, equação (1) não é contabilizada a contribuição em massa do álcool utilizado na reação, mas que passa a fazer parte da molécula do éster obtido (biodiesel). 
Por último, tem-se a análise da viscosidade dos óleos de soja novo e usado para fritura e o biodiesel. Os dados coletados no viscosímetro estão reunidos na tabela 1.

Tabela 1 - Dados de viscosidade.

\begin{tabular}{ccc}
\hline & Temperatura $\left({ }^{\circ} \mathrm{C}\right)$ & Viscosidade (mPa.s) \\
\hline Biodiesel & 26,4 & 26,9 \\
Óleo usado & 24,5 & 68,4 \\
Óleo limpo & 24,9 & 49,3 \\
\hline
\end{tabular}

De acordo com dados da ANP 07/2008, tem-se que a viscosidade cinemática do biodiesel está na faixa de 3,0 a $6,0 \mathrm{~mm}^{2} \cdot \mathrm{s}^{-1}$ a $40^{\circ} \mathrm{C}$ e sua massa especifica está em torno de 850 a $900 \mathrm{~kg} \cdot \mathrm{m}^{-3}$. Utilizando a equação (2), e fazendo as conversões de unidades, tem-se que a faixa de viscosidade do biodiesel é 2,55mPa.s $5,4 \mathrm{mPa} . \mathrm{s}$ a $40^{\circ} \mathrm{C}$.

$$
v=\frac{\mu}{p}
$$

Em que:

$\mathrm{v}=$ Viscosidade cinemática, $\mu=$ Viscosidade e $\rho=$ Massa específica.

Observou-se que a viscosidade medida no laboratório a $26,4^{\circ} \mathrm{C}$ é maior do que a faixa de viscosidade tabelada pela ANP a $40^{\circ} \mathrm{C}$, justifica-se esta diferença pelo fato de que a viscosidade foi medida a uma temperatura mais baixa do que a tabelada, com isso, se a temperatura de medida aumentar, a viscosidade diminuirá, aproximando o resultado obtido do valor tabelado.

Ao comparar a viscosidade do óleo de soja novo obtido na literatura ${ }^{5}, 41,2 \mathrm{mP}$.s a $30^{\circ} \mathrm{C}$, com o valor da viscosidade medida no viscosímetro, 49,3 mP.s à $24,9^{\circ} \mathrm{C}$, nota-se que são diferentes pelo mesmo motivo descrito para o biodiesel.

\section{Conclusão}

Neste trabalho a obtenção de biodiesel por reação de transesterificação de óleo de fritura foi utilizada como uma ferramenta simples e prática para aplicar e aprofundar conhecimentos de química do ensino médio. Além disso, foi útil também como forma de demonstrar que é possível e acessível aplicar o que é aprendido em sala de aula na transformação de resíduos e sua conversão a produtos com valor agregado, neste caso, tanto biodiesel como o glicerol tem valor comercial, o que proporcionou discussões sobre sustentabilidade, economia e energia. Por tudo isso, acredita-se que o projeto contribui decisivamente na formação dos estudantes, no seu envolvimento com problemas da sociedade, como também nas suas perspectivas para o futuro.

\section{Agradecimentos}

Os autores deste trabalho agradecem ao CNPq pelo apoio financeiro ao projeto (Edital MCTI/CNPq/SPMPR/Petrobras 18/2013; Processo: 420414/2013-4), Agradecem, ainda, à UFES e a EEEFM Miguel de Sanctis pela infraestrutura utilizada pelos alunos durante a realização deste trabalho.

\section{Referências bibliográficas}

[1] RINALDI, R., GARCIA, C., MARCINIUK, L. L., ROSSI, A. V. \& SCHUCHARDT, U. 2007. Síntese de Biodiesel: Uma proposta contextualizada de experimento para laboratório de química geral.Química Nova, vol. 30, No. 5, 1374-1380.

[2] GERIS, R., DOS SANTOS, N. A. C., AMARAL, B. A., MAIA, I. DE S., CASTRO, V. D.\& CARVALHO, J. R. M. 2007. Biodiesel de Soja - Reação de Transesterificação para Aulas Práticas de Química Orgânica. Química Nova. Vol. 30, No. 5, 1369-1373.

[3] MENEGHeTtI, S. P., MENEGHetTI, M. R. \& BRITO, Y. C. 2013. A reação de Transesterificação, Algumas Aplicações e Obtenção de Biodiesel. Revista Virtual de Química. Vol. 5, No. 1, 63-73.

[4] DINELLI, L. R., SALVATIERRA, C. R., PEIXINHO, R. T., SENE, J. J.\&CASTILHO L. N. P. 2007. Produção de Biodiesel: Um experimento em Sala de Aula. Ciência e cultura. Vol. 2, No. 2. 63-67.

[5] DA SILVEIRA, B. I. 2011. Produção de Biodiesel Analise e Projeto de Reatores Químicos.São Paulo, Biblioteca24horas.

[6] COSTA NETO, P. R., ROSSI, L. F. S., ZAGONEL, G. F. \& RAMOS, L. P. 2000. Produção de biocombustível alternativo ao óleo diesel através da transesterificação de óleo de soja usado em frituras. Química Nova, vol. 23, No. 4, 531-537.

[7] BARAÑANO, A. G., ABREU, A. S. \& BOTINHA, B. R. 2012. Metodologia para produção de biodiesel, em escala de bancada, utilizando óleo de soja e etanol. $2^{\circ}$ Encontro de Engenharia Química da UFES. Alegre. 
[8] LÔBO, I. P., FERREIRA \& S. L. C., 2009.Biodiesel: parâmetros de qualidade e métodos analíticos. Química Nova. Vol. 32, No. 6,1596-1608. 